\title{
Scar-Free Wound Healing Following Full-Thickness Cutaneous Wounding in the Tail and Body of Scincella tsinlingensis
}

\author{
Cicatrización de Heridas sin Cicatrices Luego de Heridas Cutáneas \\ de Espesor Total en la Cola y el Cuerpo de Scincella tsinlingensis
}

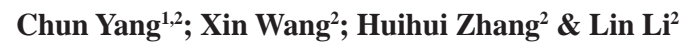

\begin{abstract}
YANG, C.; WANG, X.; ZHANG, H. \& LI, L. Scar-free wound healing following full-thickness cutaneous wounding in the tail and body of Scincella tsinlingensis. Int. J. Morphol., 39(4):1139-1146, 2021.

SUMMARY: The cutaneous wounds of trunk and tail healing scar-free or with scar were different in lizard species. Fullthickness cutaneous injuries of tail and body of Scincella tsinlingensis were examined by histomorphological and immunohistochemistrical methods. The results showed that all injuries healed without scarring. The process of the wound healing of S. tsinlingensis involved hemostasis, re-epithelialization, proliferation and remodelling, which also could be further subdivided into six stages. Stage I, 0-2 day post wound (dpw), the blood oozed gradually, no obvious wound contraction, minimal blood loss. Stage II, 2-10 dpw, the wound bed covered by the fibrin clot of blood, tissue fluid and tissue debris. Stage III, 7d-15 dpw, the wrinkled wound epitheliums was gradually stratified, and its surface was keratinized and exfoliated. Stage IV, 10-28 dpw, pigment cells were distributed at the boundary between epidermis and dermis, with few blood vessels and no granulation tissue formation. Stage V, 20-70 dpw, opaque scales covered the wound epithelium with randomly scattered melanophores in the base of the epidermis. Stage VI, 45-135 dpw, the epidermis and dermis restored to the thickness of the original skin. Regenerated scales were similar to scales of the uninjured dermis. The positive immunostaining of matrix metalloproteinases- 9 , cytokeratin 6 , alpha smooth muscle actin, caspase 3 and transforming growth factor- $\beta 3$ showed the specificity of healing period and different stages, which participated in skin wounds healing of $S$. tsinlingensis.
\end{abstract}

KEY WORDS: Scincella tsinlingensis; Skin wound healing; Histology; Immunohistochemistry.

\section{INTRODUCTION}

Skin is composed of epidermis and dermis in animals and humans, which covers the entire surface of the body with frequently occurring injuries (Abe et al., 2020). Skin wound healing involves an overlapping cascade of tissue events, i.e., hemostasis, inflammation, proliferation and remodeling (Jourdan et al., 2019; Korntner et al., 2019). The tissue events of the last three stages determine whether the wound is scar-free or whether the abnormal healing process causes extensive angiogenesis and collagen deposition to form a scar (Poetschke \& Gauglitz, 2016; Stoica et al., 2020). In non-amniote vertebrates, the wound bed involve a more rapid closure of the wound epithelium, a delay vasculogenesis and collagen deposition without scarring (Peacock et al., 2015; Abe et al.). All mammals but a few species are unable to regenerate dermis, and form a scar after a deep injury (Seifert et al., 2012). Skin regeneration of the lizard tail and body has garnered much attention as wound healing models (McLean \& Vickaryous,
2011). Investigation of skin regeneration using various vertebrate models, including lizards, could lead to the realization of scar-free skin regeneration in humans (Alibardi \& Toni, 2005).

During wound repair, the quantity and quality of new blood vessels formation is imperative for efficient tissue restoration (Yu et al., 2014; Naito et al., 2020).The inhibition or acceleration of angiogenesis can suppress the spontaneous regenerative response of mice and zebrafish. Comparative studies of skin regeneration together with the tail and body of non-mammalian amniotes is represented by the lizard (Alibardi \& Toni). Scar-free wound healing is not a universal feature of lizard reptiles. Scar-free skin regeneration is reported in the leopard gecko (Eublepharis macularius) after a deep injury (Peacock et al.; Payne et al., 2017), while only the tail wound of Anolis carolinensis can regenerate without scars and produce keratinized scales,

\footnotetext{
${ }^{1}$ Prof., Modern College of Arts and Sciences, Shanxi Normal University, Linfen, Shanxi Province, P.R. China, 041004.

${ }^{2}$ School of Life Sciences, Shanxi Normal University, Linfen, Shanxi Province, P.R. China, 041000.
} 
but the color of the regenerated skin cannot be restored (Wu et al., 2014). The Scincella tsinlingensis, an endemic lizard species to China, can regenerate their tails after autotomy (Yang et al., 2021). The studies to investigate the pattern of expression of markers associated with wound healing in S. tsinlingensis help to clarify elucidation of the mechanisms underlying the skin regeneration.

Matrix metalloproteinases-9 (MMP-9) play important role in extracellular matrix (ECM) remodeling in a variety of animals. In the early wound healing phase during amphibian regeneration, MMP-9 is upregulated and act as an important factor to initiate the dedifferentiation of the mesenchymal tissues. Activity levels of MMP-9 are evaluated during tail regeneration in Hemidactylus flaviviridis (Pillai et al., 2020). Cytokeratin 6 is produced in activated reptilian keratinocytes (Alibardi \& Toni). Caspase 3(C3), the effector of the caspase-mediated apoptotic program, is widely recognized as a definitive marker of programmed cell death. Elevated levels of transforming growth factor- $\beta 3$ (TGF- $\beta 3$ ) promote scar-free wound healing (Delorme et al., 2012). Alpha smooth muscle $\operatorname{actin}(\alpha-$ SMA $)$ belongs to the family of the six conserved actin isoforms. $\alpha$-SMA is essential for the formation of new blood vessels (Rafii et al., 2016) and abundant in vascular smooth muscle cells (SMCs) (Skalli et al., 1989). In light of this information, localization of MMP-9, cytokeratin 6, $\alpha$-SMA, C3 and TGF- $\beta 3$ are examined by immunohistochemistry after full-thickness cutaneous wounding in the tail and body of $S$. tsinlingensis.

\section{MATERIAL AND METHOD}

Experimental animal. The $S$. tsinlingensis were captured from the hilly areas of Qiliyu forest in Taiyue Mountain, Shanxi, China $\left(110^{\circ} 40^{\prime}-112^{\circ} 21^{\prime} \mathrm{E}, 36^{\circ} 21^{\prime}-36^{\circ} 45^{\prime} \mathrm{N}\right)$. Experiments were carried out according to protocols approved by animals care guidelines of the Ethical Committee of Shanxi Normal University. The lizards were kept in a terrarium with a 14:10 photoperiod, a room temperature of $24{ }^{\circ} \mathrm{C}$ and an ambient humidity of $40-50 \%$, fed with a diet of insects and water in daily.

Biopsies. All adult individuals of both sexes of the lizards were randomly selected as the experimental object. The animals were placed at $4{ }^{\circ} \mathrm{C}$ for 20 minutes for hypothermic anesthesia, then laid on pre-cooled culture plate and fullthickness excision cutaneous wounds were created using a $1.5 \mathrm{~mm}$ disposable biopsy tool (Integra TMMiltex®). The skin wounds of the trunk and original tail were distributed along the dorsal midline, $1 \mathrm{~cm}$ before and after the intersection of the dorsal midline and the hind limbs, respectively. Then, the animals were kept under the same conditions and the healing process was observed.

Tissue collection. After receiving the full-thickness excision biopsies, the lizards were permitted to heal. At select time points (0 dpw, 2 dpw, 7 dpw, 14 dpw, $25 \mathrm{dpw}, 45 \mathrm{dpw}$ ). Animals were humanely killed at $-20^{\circ} \mathrm{C}$, the tissues from body and tail was fixed in $4 \%$ paraformaldehyde for 1-3 days, decalcified for 1-3 days, and changed every $24 \mathrm{~h}$. Then, samples were dehydrated with graded alcohols, cleared in xylenes, embedded in paraffin wax. Sections were cut at 10 $\mu \mathrm{m}$ on a rotary microtome and stained by hematoxylin-eosin (H-E) or Masson's trichrome. The sections were observed with BX-51 light microscope.

Immunohistochemistry. Slides were dewaxed with xylene, rehydrated, incubated dark in $3 \% \mathrm{H}_{2} \mathrm{O}_{2}$ for 30 minutes at a room temperature, then rinsed three times with PBS (0.1M, PH 7.4), and blocked with $5 \%$ BSA to prevent non-specific binding. Sections were incubated with primary antibodies overnight at $4{ }^{\circ} \mathrm{C}$. Following primary antibodies and were used: anti rabbit forMMP-9, cytokeratin $6, \alpha-$ SMA, C3 and TGF-ß3(1:100, Booster). Negative control slides were replaced primary antibody with PBS. After rinsing in the buffer, sections were incubated with biotinylated goat antimouse/rabbit IgG (1:100, Booster) for $4 \mathrm{~h}$ at room temperature, subsequently incubated with SABC and visualized using DAB. All pictures were obtained with Olympus BX-51digital imaging system and conducted by Photoshop CS6.

\section{RESULTS}

Stage I (0-2 dpw). During stage I, the trunk and tail wounds showed open wounds, the tissues were exposed, there was no obvious bleeding on the surface of the wound at the beginning of the wound. The wound edge collapsed slowly and began to contract, the open wound area decreased and the wound edge began to appear melanosis, which could be the initial mechanism to protect the wound surface. Fullthickness excision cutaneous wounds of the tail and trunk were confirmed by histology, and sometimes the underlying muscles were involved (Figs. 1-A and $\mathrm{H}$ ). The wound of the tail and trunk began to reepithelialize, and the wound epithelium was incomplete and consisted of 1-4 layers of round or squamous cells on $2 \mathrm{dpw}$ (Figs. 1-D and K). The epithelial cells stained with H.E were pink and the underlying muscle tissue was blue-purple (Figs. 1-C and J). Masson's trichrome showed that the wound epithelium was red, while the lower muscle tissue was turquoise (Figs. 1-B and I). 
At the end of the stage I, cytokeratin 6 (Figs. 1-G and N) and MMP-9 (Figs. 1-F and M) showed immunopositive, and the expression of MMP-9 in wound epithelium were strong. a-SMA expressed myofibroblasts

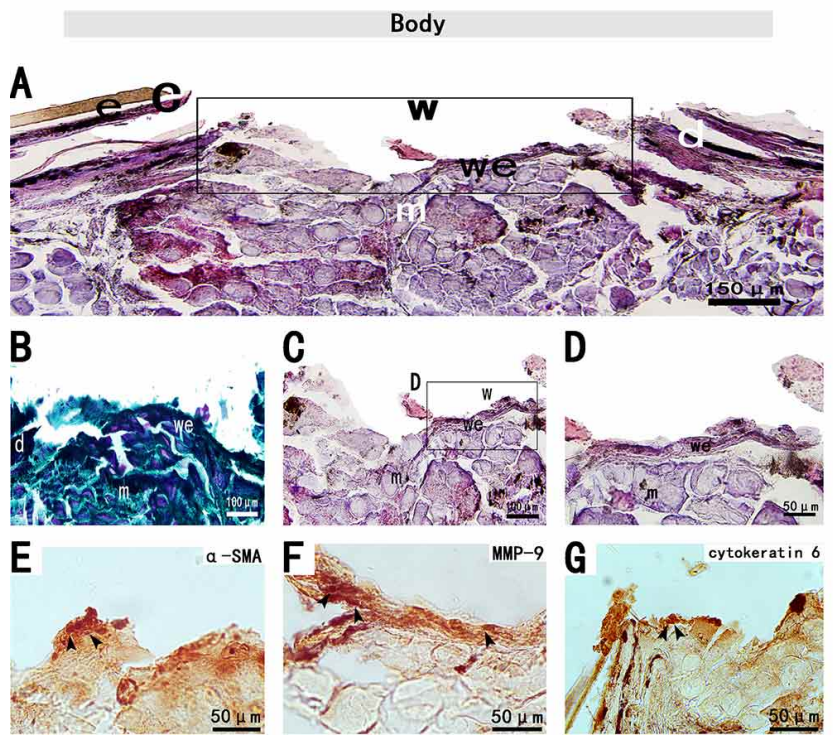

were present at the wound (Figs. 1-E and L). Isolated cells from the original epidermis and dermis were immunopositive for $\mathrm{C} 3$. No TGF- $\beta 3$ immunopositive cells were observed at this stage.

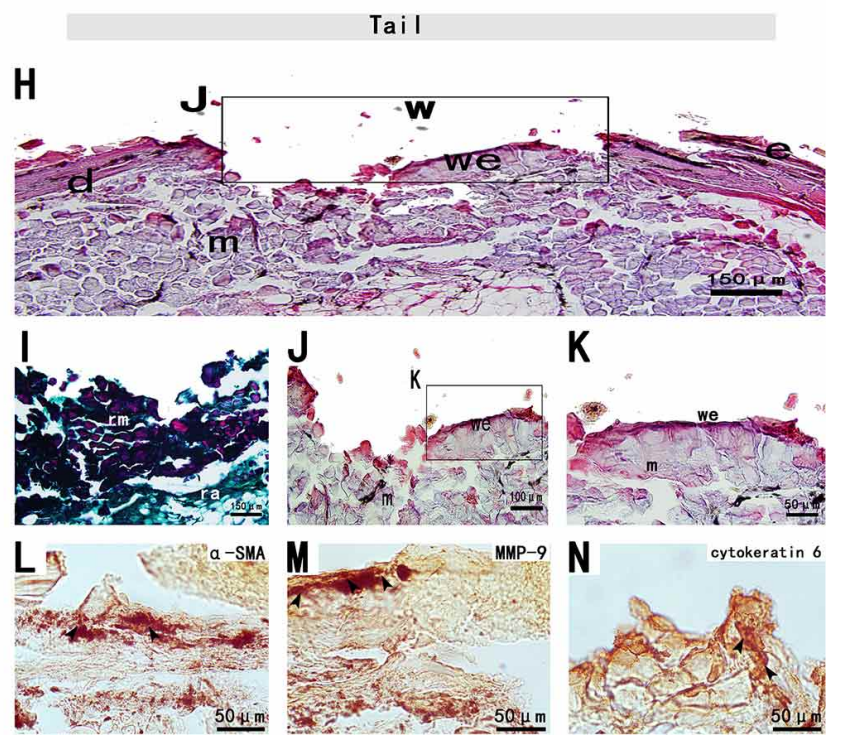

Fig. 1. Stage I of the tail and body scar-free wound healing of S. tsinlingensis. A and H. Transverse section of the wound area of the body and the tai; B and I. Higher magnification image of the wound area of the body and the tai, stained with Masson's trichrome; C and J. Closer view of the region identified in panel (A) and (H); D and K. Closer view of the region identified in panel (C) and (J); E-G and LN. The body and tail wound areas, stained with a-SMA, MMP-9 and cytokeratin 6 by immunohistochemistry. The Arrows indicate immunopositive cells. epidermis (e), dermis (d), muscle (m), wound area (w), wound epithelium (we).

Stage II (2-10 dpw). During stage II, blood clots formed at the wound bed of the trunk and tail, which gradually thickened and covered the wound surface (Figs. 2-A and I). The histological results showed that the wound epithelium began to form beneath the clot and gradually deepened into the clot, and the wound epithelium was wrinkled evenly (Figs. 2-D and L), and reepithelialization was not completed until the third stage. Blood clots were easily lost during tissue remodeling, indicating poor adhesion to the wound bed and high melanin content at the wound site. The clots and epithelial cells of the wound stained with H.E were pink and the underlying muscle tissue was blue-purple (Figs. 2-C and $\mathrm{K})$. Masson's trichrome showed that the clot and wound epithelium were red and the muscle tissue below it was turquoise (Figs. 2-J).

There were cytokeratin 6 immunopositive cells (Figs. 2-H and P) and MMP-9 immunopositive cells (Figs. 2-G and $\mathrm{O}$ ) in the wound epithelium, and $\alpha$-SMA immunoreactive myofibroblasts were more abundant than the first stage stage I (Figs. 2-F and N). C3 immunopositive cells were observed at the wound surface (Figs. 2-E and M), without TGF- $\beta 3$ immunostaining.
Stage III (7-15 dpw). During stage III, the gross morphological results showed that the epithelium of trunk and tail wound was wrinkled. The clot of the trunk disappeared, and the wound was completely covered with epithelium (Figs. 3-A). Small round cells accumulated in the matrix of loose tissue, with clear boundaries between undamaged dermis (Figs. 3-D). However, the clot of the tail still exists (Fig 3-9 I), the number of cells in the wound matrix is less than that of the trunk, and the extracellular matrix is less (Fig .3-9 L). Inflammation of the wound site ended at this stage. Wound epithelium began to keratinize and melanin decreased, luteal layer appeared below epidermis, tail and trunk wound epithelium gradually stratified, wound epidermis exfoliated cuticle (Fig .3-9 D). The H.E. staining results showed that the exfoliated wound epidermis and the cuticle of the wound epidermis were pink (Figs. 3-C and K), while Masson's trichrome showed a mixture of green and red (Figs. 3-B and J).

Mesenchymal cells at the wound site were weakly immunopositive for MMP-9(Figs. 3-G and O). The regenerated epithelial fibroblasts and perivascular cells were immunopositive for $\alpha$-SMA (Figs. 3-F and N). The wound epithelial cells maintained cytokeratin 6 expression (Figs. 3-H and P). A large number of C3 immunopositive cells were observed in the dermis (Figs. 3-E and M). 
Body

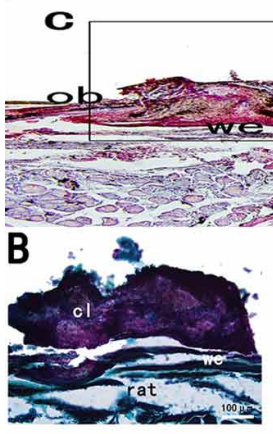

E

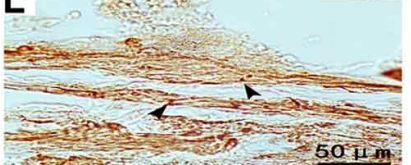

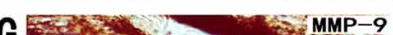
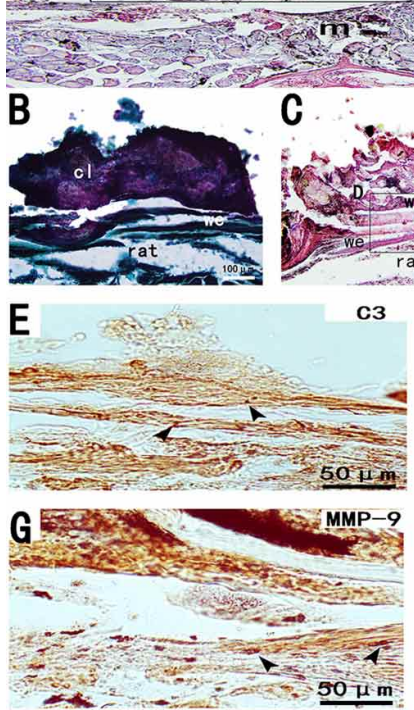

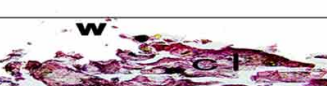

7
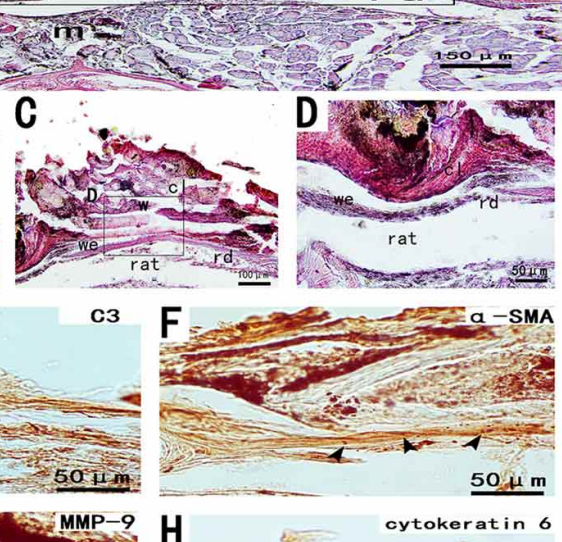

H

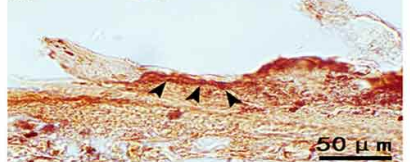

Tail

I
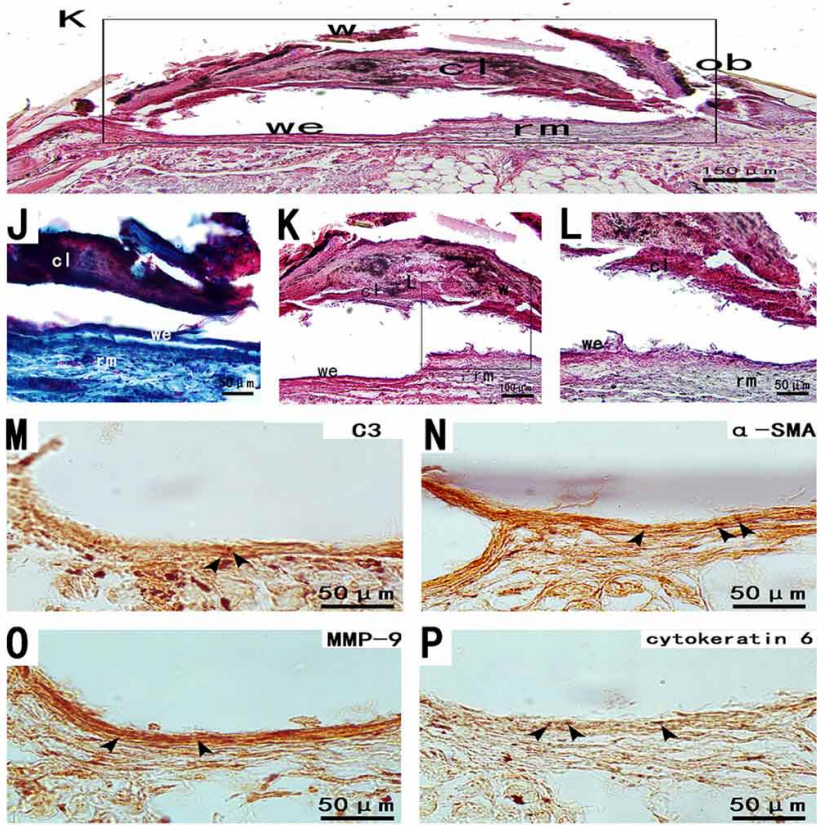

Fig. 2. Stage II of the tail and body scar-free wound healing of S. tsinlingensis. Exudate clot (cl), regenerated dermis (rd), adipose tissue (at).

Body

\section{A}
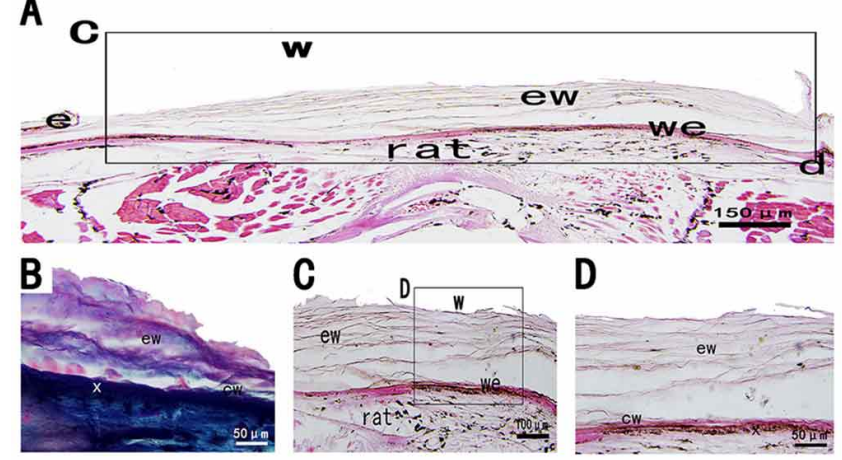

D
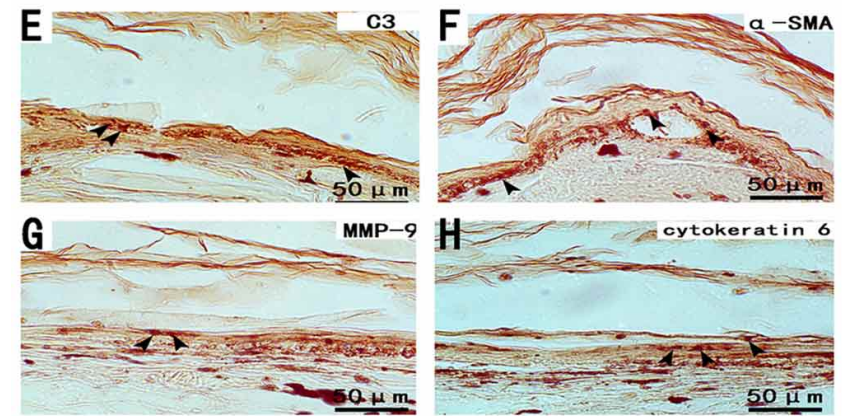

Tai I

I
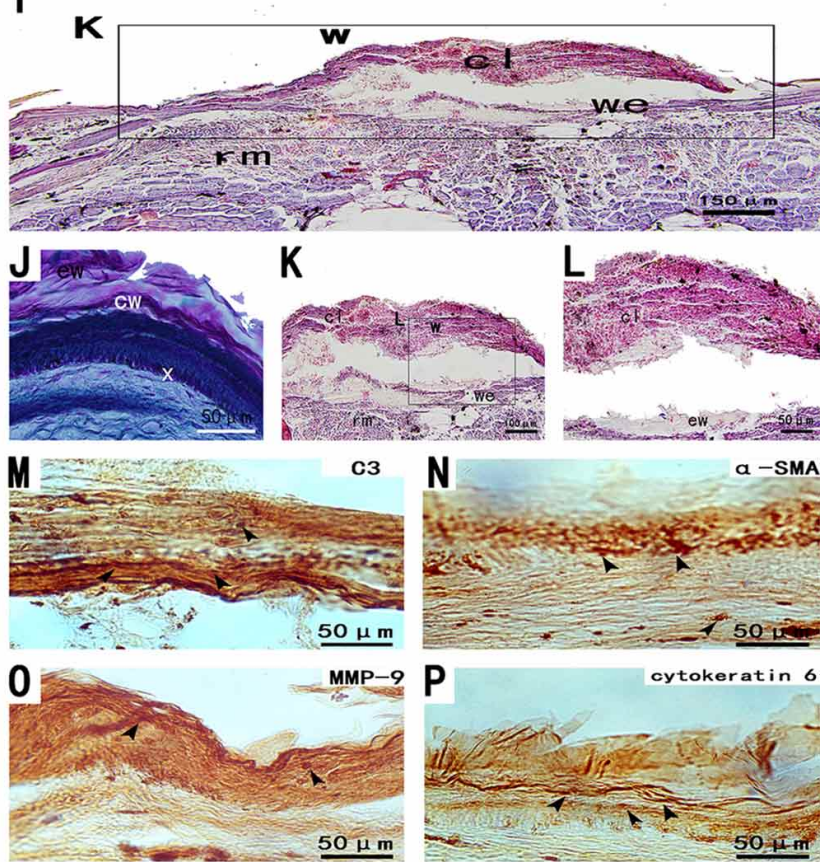

Fig. 3. Stage III of the tail and body scar-free wound healing of S. tsinlingensis. Exfoliating wound (ew), epidermis (e), corneous layer of the wound epidermis (cw), xanthophore layer (x). 
Stage IV(10-28 dpw). During stage IV, the caudal and trunk wounds exposed a smooth and tight wound epithelium without squamous coverage. The caudal clot detached from the wound, showing intact wound epithelium (Figs. 4-H). A exfoliated cuticle was observed in the wound epidermis of the tail and trunk cadres (Figs. 4-A and H), and the boundary between the epidermis and the undamaged dermis was obvious, thicker than the original epidermis, and the blood vessels in the regenerated tissue were obvious (Figs. 4-C and J). Pigment cells were observed at the junction of epidermis and dermis (Figs. 4-D and K). The regenerated horn cortex was yellow and brown, the regenerated $\beta$-layer, middle layer and $\alpha$-layer were pink, the regenerated germinal layer was

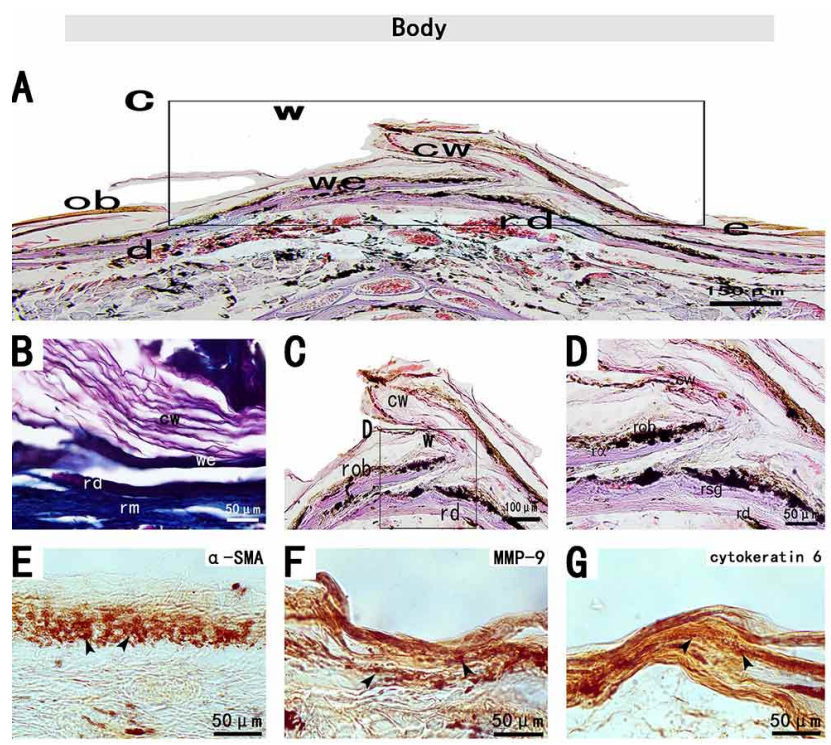

blue and purple, and the regenerated dermis was pink. (Figs. 4-D and K). The H.E. staining or Masson's trichrome staining results showed extensive escalation and reticular collagen deposition, with low cellularity (Figs. 4-B and I).

Immunohistochemical results showed that wound epithelium was consistently immunopositive for cytokeratin 6 (Figs. 4-G and N). The wound epithelium with a small number of apoptotic C3 positive cells was still MMP-9 immunopositive (FigureFigs. 4-F, M). Perivascular cells were still immunopositive for $\alpha$-SMA (Figs. 4-F and L), but myofibroblasts showed negtive. No TGF- $\beta 3$ positive cells were observed.

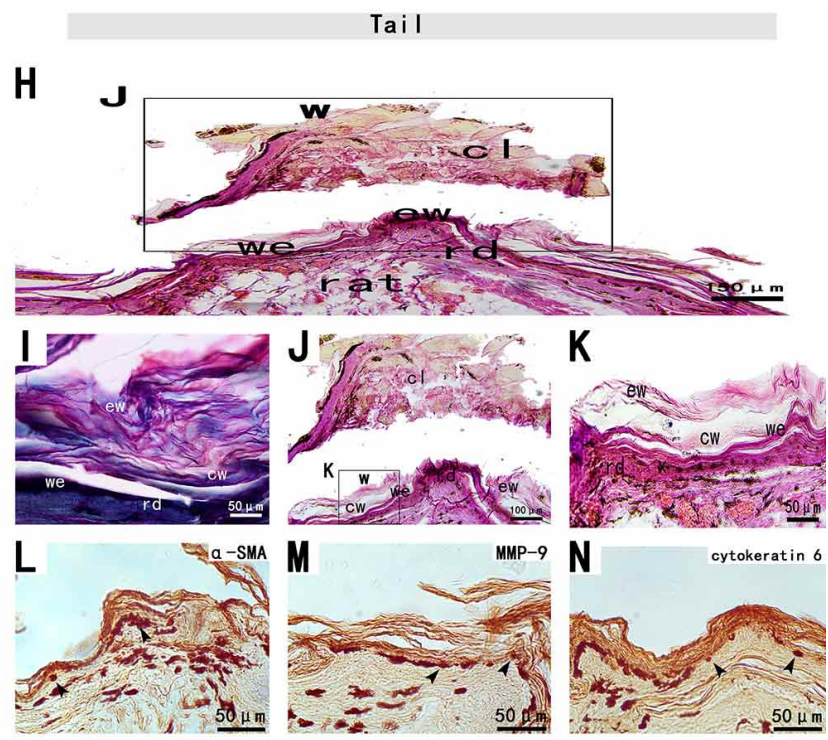

Fig. 4. Stage IV of the tail and body scar-free wound healing of $S$. tsinlingensis. regenerated muscle (rm), regenerated oberhautchen (rob), regenerated beta layer (rb), regenerated alpha layer (ra), regenerated dermis (rd), regenerated stratum germinativum (rsg).

Stage V (20-70 dpw). During stage V, the wound epithelium keratinizes and begins to form scales. Histological results showed that the wound epithelium differentiated and formed a cuticle (Figs. 5-A and H). The epidermis of regenerated skin was relatively thin and covered by the cuticle (Figs. 5$\mathrm{C}$ and $\mathrm{J}$ ). The wound epithelium invaginated into a hinged area, which in turn gave rise to scales. The wound epithelium of the caudal and trunk showed similar histomorphology (Figs. 5-A and D). The interface between the intact dermis and the provisional tissue was not clear (Figs. 5-H). The wound epithelium was four to seven cell layers thick (Figs. 5-D and K). Both H.E. staining and Masson's trichrome of wound bed revealed the regenerated horn cortex, $\beta$-layer, middle-layer, $\alpha$-layer, and the regenerated germinal layer (Figs. 5-B and I).

The trunk and tail wounds showed abundant reticular collagen, with low cellularity. Only regenerative epithelium had an immune response to cytokeratin 6 (Figs. 5-G and N).
MMP-9 (Figs. 5-F and M) and TGF- $\beta 3$ (Figs. 5-E and L) were positive in fibroblasts.

Stage VI (45-135 dpw). During Stage VI, the pigmentation on the wound surface was obvious, and the scales gradually formed from the front edge of the wound to the inside over time. This stage was characterized by complete differentiation of the epidermis, dermis and scales. In the trunk and tail wounds, the regenerated epidermis and the undamaged epidermis without obvious boundary (Figs. 6-A and $\mathrm{H}$ ) were composed of the angular cortex, $\beta$-layer, middlelayer, $\alpha$-layer, and germinal layer in the same way, and the epidermis folded into a stranded region. The regenerated dermis was composed of fibroblasts, loose connective tissue, and collagen (Figs. 6-D and K).

Only the basal layer of regenerated epidermis was immunopositive for cytokeratin 6 (Figs. 6-G and N). Fibroblasts from the regenerated skin of the tail and trunk 
were immunopositive to MMP-9 (Figs. 6-F and M) and TGF- 33 (Figs. 6-E and L).

Body

A
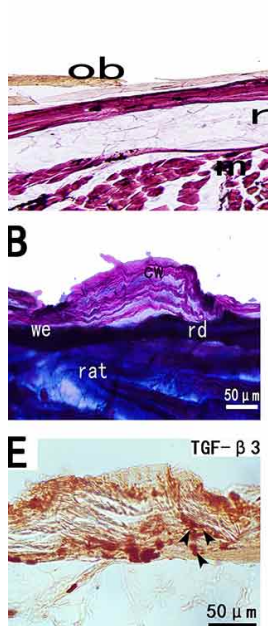

\section{$\mathbf{C} \mathbf{w}$}

av
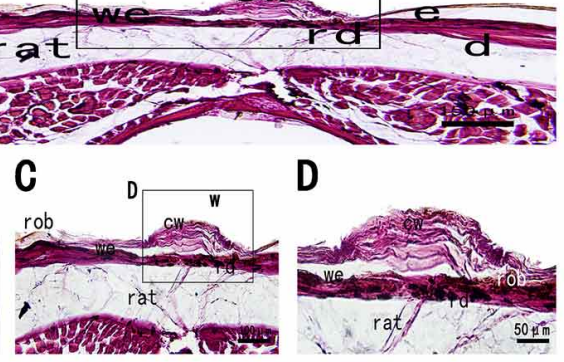

D

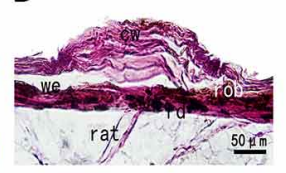

MMP-9 $\mathbf{G}$
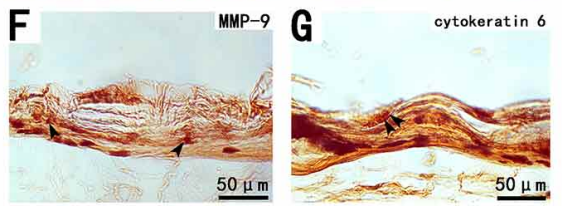

H
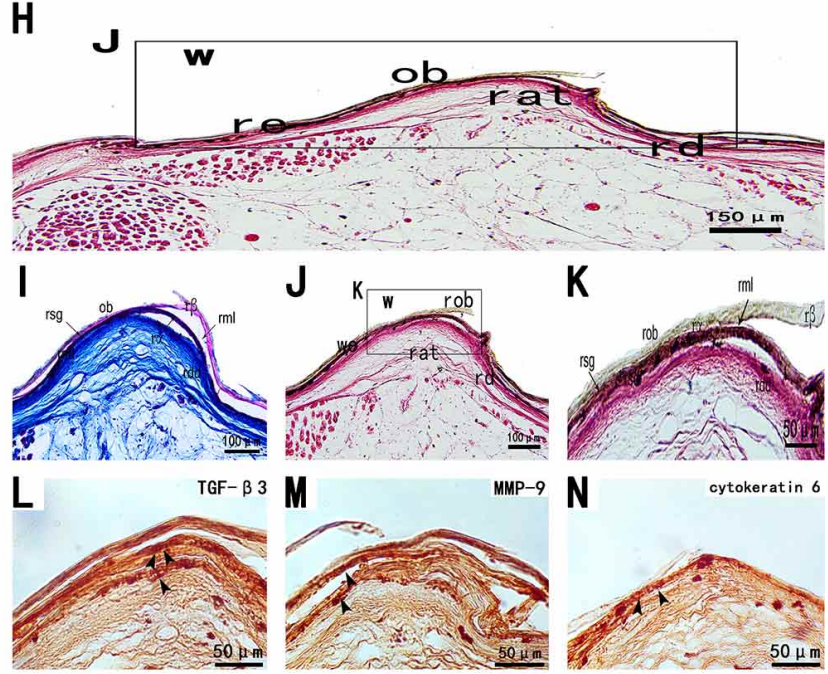

Tai
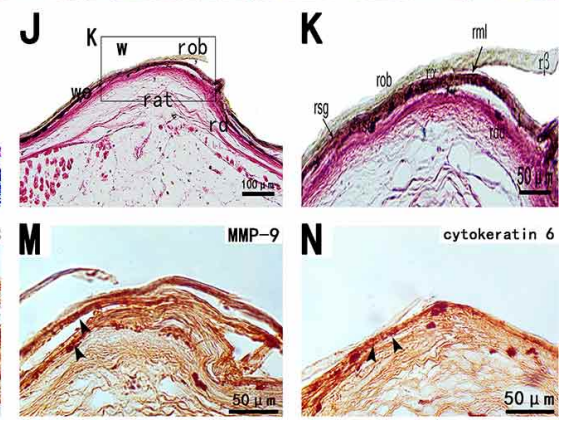

Fig. 5. Stage V of the tail and body scar-free wound healing of S. tsinlingensis. Oberhautchen (ob), regenerated mesos layer (rml), regenerated stratum germinativum (rsg), regenerated superficial dermis (rsd), regenerated deep dermis (rdd), corneous layer of the wound epidermis (cw).

\section{Body}

A
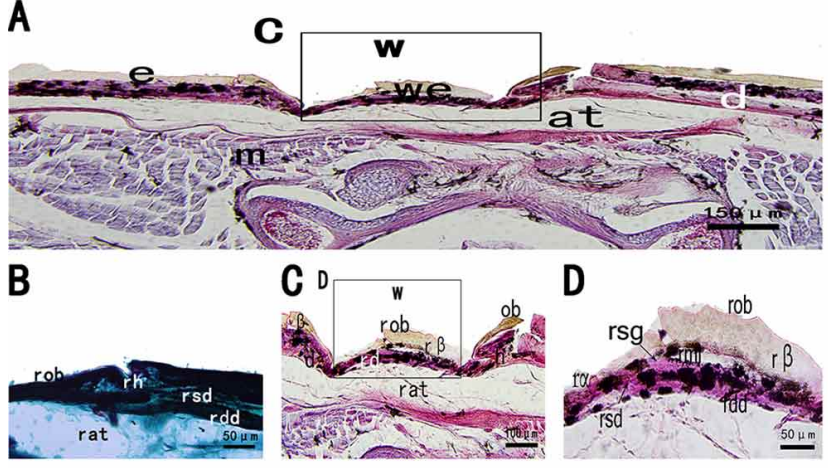

E
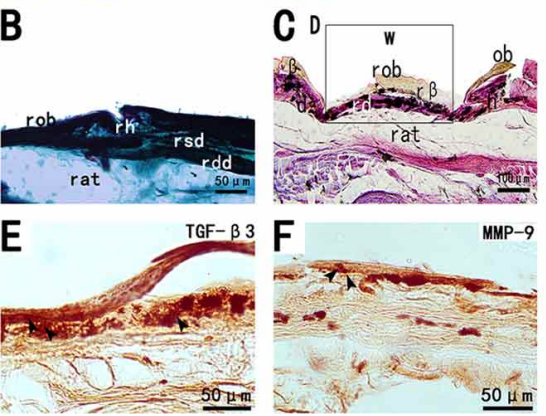

D
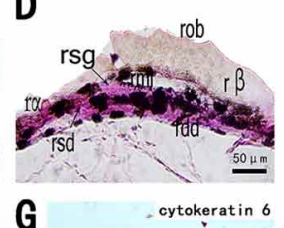

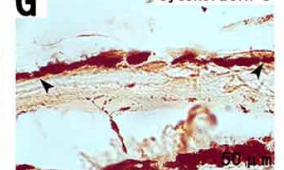

Tail
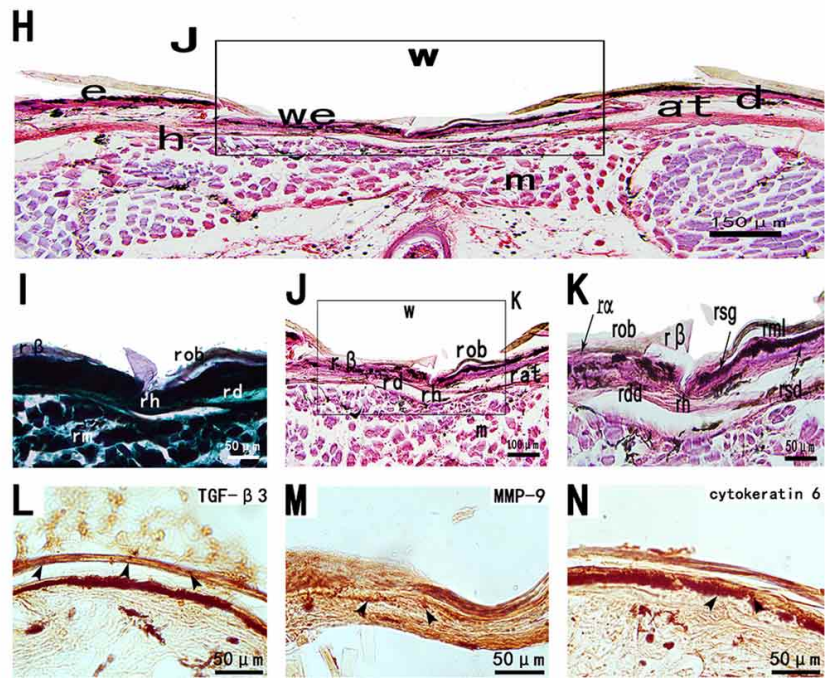

Fig. 6. Stage VI of the tail and body scar-free wound healing of S. tsinlingensis. regenerated superficial dermis (rsd), regenerated deep dermis (rdd), regenerated hinge region (rh).a

\section{DISCUSSION}

The skin of the trunk and tail in S. tsinlingensis showed scar-free cutaneous wound healing following full-thickness excisional injury, which was consistent with E. macularius. After wound formation, the caudal wound had less bleeding and was covered by blood clot within $12 \mathrm{~h}$, while the trunk cadre had more bleeding and was covered by blood clot within
$24 \mathrm{~h}$. There were no signs of infection in the wound sites of the tail and trunk. Compared with scar healing, caudal and trunk wounds were characterized by rapid re-epithelialization, delayed collagen deposition and angiogenesis, and no granulation tissue formation. Eventually, pigmented scales were formed, and the skin heals without scar (Peacock et al.). 
The whole skin of $S$. tsinlingensis was removed as an open wound, which could be quickly closed during the wound healing process. The wound closure and reepithelialization of the trunk and tail could be completed within $7 \mathrm{dpw}$, and the closure time of the wound was 7-15 dpw due to the large wound surface in the regeneration process of tail severing. The healing time range of this species was roughly the same as that of other lizards. For example, re-epithelialization could be completed within $5 \mathrm{dpw}$ for the body and tail wounds of leopard print keeper, and within 10dpw after tail amputation (Delorme et al.). The $2 \mathrm{~mm} \mathrm{x}$ $5 \mathrm{~mm}$ full-thickness skin biopsy wound of the green anile lizard could be re-epithelialized within $7 \mathrm{dpw}$ and healed without scar within $45 \mathrm{dpw}$ (Wu et al.). Wound healing in ectoderms was affected by the external environment and temperature, so its closing rate varied with the experimental environmental conditions (Smith et al., 1988). Therefore, rapid wound closure was a hallmark of scarless wound healing. Although the role of rapid wound closure epithelium in scarless wound healing was unclear, it provided a reference for reducing scar formation.

Dermal repair not only played an important role in wound healing, but also contributed to the regeneration of skin appendages (Driskell et al., 2013). Dermal repair involved collagen deposition and fibroblast proliferation. The experimental results showed that the beginning time of collagen deposition in the process of scarless healing of $S$. tsinlingensis was almost the same as that of other scarless species. The collagen content in the skin wound of $S$. tsinlingensis increased further from $14 \mathrm{dpw}$ to $25 \mathrm{dpw}$. The process of fiber proliferation was similar to that of cicatricial wound healing in the African spinyrat (Seifert et al.). In contrast, fibrosis in mammalian scar wounds began at 3-4 dpw (Greaves et al., 2013). Therefore, early collagen deposition caused tissue fibrosis to form scar, while delayed collagen deposition led to scarless wound healing.

Subcutaneous tissue was consisted of adipocytes and ECM. A large number of adipocytes were found in the regenerated tail of $S$. tsinlingensis. Hypodermic tissue in the tail of a lizard was an important part of fat storage, and wellnourished individuals produced a large number of adipocytes (Lynn et al., 2013). During the healing process of reptile skin wound, fibroblasts migrated from the skin surface. Therefore, adipose tissue repair after skin trauma in lizards was associated with deep dermis. ECM provided a suitable microenvironment for the expression and separation of growth factors, which made white blood cells secrete protease to decompose clots and extracellular matrix, and promoted cell division and migration. The deposition of ECM began during stage III of wound healing in $S$. tsinlingensis, which was consistent with other scarless healing species.
The MMP-9 immunopositive cells in wound epithelial cellssuggested that MMP-9 involved in the remodeling of the extracellular matrix. During stages II-III, cytokeratin 6 immunopositive keratinocytes were increased, the data revealed that the epidermis were differentiating. During stages II-III, the $\alpha$-smooth muscle actin immunopositive myofibroblasts were presented in wound surfaces to promote wound close. And then, the neutrophils, macrophages and fibroblast demonstrated immunoreactivity for C3 that can inhibition scare formation. During stages VVI, the fibroblast and vascular endothelial cells demonstrated immunoreactivity for transforming growth factor- $\beta 3$ that suggested the transforming growth factor can inhibition granulation tissue formation. The expression of $\alpha$-SMA within the healing wound was similar to that of other regeneration competent species (Desmoulière et al., 2005), but it was different from that in the leopard gecko $(E$. macularius), no myofibroblasts were found in the leopard gecko (E. macularius), whereas $\alpha$-SMA positive myofibroblasts were present at the wound site following tail loss (Peacock et al.). Myofibroblasts also secreted abundant type I and type III collagen to the wound bad, hence persistent and abundant presence of myofibroblasts led to scar formation. During the healing wound in most mammals, myofibroblasts were continuously and abundantly expressed (Desmoulière et al.).

In conclusion, the results of this study showed that the skin of the trunk and tail in S. tsinlingensis showed scarfree cutaneous wound healing following full-thickness excisional injury. The localization of MMP-9, cytokeratin6, $\alpha$-SMA, C3 and TGF- $\beta 3$ positive cells showed the specificity of healing period and different stages, and participated in skin wounds healing of S. tsinlingensis.

\section{ACKNOWLEDGEMENTS}

This research was supported by a grant from the Scientific Research Project of Modern College of Arts and Sciences, Shanxi Normal University (Project No. 2020JCYJ15).

YANG, C.; WANG, X.; ZHANG, H. \& LI, L. Cicatrización de heridas sin cicatrices luego de heridas cutáneas de espesor total en la cola y el cuerpo de Scincella tsinlingensis. Int. J. Morphol., 39(4):1139-1146, 2021.

RESUMEN: En las diferentes especies de lagartos las heridas cutáneas del tronco y la cola sin cicatrices, o con algún tipo de cicatriz son diversas. En este estudio se examinaron las heridas cutáneas de espesor total de la cola y el cuerpo de Scincella 
tsinlingensis mediante métodos histomorfológicos e inmunohistoquímicos. Los resultados indicaron que todas las lesiones sanaron sin cicatrices visibles. El proceso de cicatrización de heridas de $S$. tsinlingensis implicó hemostasia, reepitelización, proliferación y remodelación, que también podrían subdividirse en seis etapas. Etapa I, 0-2 días después de la herida (dph), la sangre filtraba gradualmente, sin contracción evidente de la herida, con pérdida mínima de sangre. Etapa II, 2-10 dph, el lecho de la herida estaba cubierto por el coágulo de sangre, líquido tisular y restos tisulares de fibrina. Etapa III, 7-15 dph, los epitelios de la herida se estratificaron gradualmente y su superficie se queratiniza y exfolia. Etapa IV, 10-28 dph, las células pigmentarias se distribuyeron en el límite entre la epidermis y la dermis, con pocos vasos sanguíneos y sin formación de tejido de granulación. Etapa V, 20-70 dph, escamas opacas cubrieron el epitelio de la herida con melanóforos dispersos al azar en la base de la epidermis. Etapa VI, 45-135 dph, la epidermis y la dermis restauradas al grosor de la piel original. Las escamas regeneradas eran similares a las escamas de la dermis sin herida. La inmunotinción positiva de metaloproteinasas9 de matriz, citoqueratina 6 , actina de músculo liso alfa, caspasa 3 y factor de crecimiento transformante- $\beta 3$ mostró la especificidad del período de curación y las diferentes etapas, que participaron en la curación de heridas cutáneas de S. tsinlingensis.

PALABRAS CLAVE: Scincella tsinlingensis; Cicatrización cutanea; Histología; Immunohistoquimica.

\section{REFERENCES}

Abe, G.; Hayashi, T.; Yoshida, K.; Yoshida, T.; Kudoh, H.; Sakamoto, J.; Konishi. A.; Kamei, Y.; Takeuchi, T.; Tamura, K.; et al. Insights regarding skin regeneration in non-amniote vertebrates: Skin regeneration without scar formation and potential step-up to a higher level of regeneration. Semin. Cell Dev. Biol. Apr, 100:109-21, 2020.

Alibardi, L. \& Toni, M. Wound keratins in the regenerating epidermis of lizard suggest that the wound reaction is similar in the tail and limb. $J$. Exp. Zool. A Ecol. Genet. Physiol., 303(10):845-60, 2005.

Delorme, S. L.; Lungu, I. M. \& Vickaryous, M. K. Scar-free wound healing and regeneration following tail loss in the leopard gecko, Eublepharis macularius. Anat. Rec. (Hoboken)., 295(10):1575-95, 2012.

Desmoulière, A.; Chaponnier, C. \& Gabbiani, G. Tissue repair, contraction, and the myofibroblast. Wound Repair Regen., 13(1):7-12, 2015.

Driskell, R. R.; Lichtenberger, B. M.; Hoste, E.; Kretzschmar, K.; Simons, B. D.; Charalambous, M.; Ferron, S. R.; Herault, Y.; Pavlovic, G.; Ferguson-Smith, A. C.; et al. Distinct fibroblast lineages determine dermal architecture in skin development and repair. Nature, 504(7479):277-81, 2013.

Greaves, N. S.; Ashcroft, K. J.; Baguneid, M. \& Bayat, A. Current understanding of molecular and cellular mechanisms in fibroplasia and angiogenesis during acute wound healing. J. Dermatol. Sci., 72(3):20617, 2013.

Jourdan, M.; Madfes, D. C.; Lima, E.; Tian, Y. \& Seité, S. Skin care management for medical and aesthetic procedures to prevent scarring. Clin. Cosmet. Investig. Dermatol., 12:799-804, 2019.

Korntner, S.; Lehner, C.; Gehwolf, R.; Wagner, A.; Grütz, M.; Kunkel, N.; Tempfer, H. \& Traweger, A. Limiting angiogenesis to modulate scar formation. Adv. Drug. Deliv. Rev., 146:170-89, 2019.

Lynn, S. E.; Borkovic, B. P. \& Russell, A. P. Relative apportioning of resources to the body and regenerating tail in juvenile leopard geckos (Eublepharis macularius) maintained on different dietary rations. Physiol. Biochem. Zool., 86(6):659-68, 2013.
McLean, K. E. \& Vickaryous, M. K. A novel amniote model of epimorphic regeneration: the leopard gecko, Eublepharis macularius. BMC Dev. Biol., 11:50, 2011.

Naito, H.; Iba, T. \& Takakura, N. Mechanisms of new blood-vessel formation and proliferative heterogeneity of endothelial cells. Int. Immunol., 32(5):295-305, 2020.

Payne, S. L.; Peacock, H. M. \& Vickaryous, M. K. Blood vessel formation during tail regeneration in the leopard gecko (Eublepharis macularius): The blastema is not avascular. J. Morphol., 278(3):380-9, 2017.

Peacock, H. M.; Gilbert, E. A. B. \& Vickaryous, M. K. Scar-free cutaneous wound healing in the leopard gecko, Eublepharis macularius. J. Anat., 227(5):596-610, 2015.

Pillai, A.; Patel, S.; Ranadive, I.; Desai, I. \& Balakrishnan, S. Fibroblast growth factor-2 signaling modulates matrix reorganization and cell cycle turnover rate in the regenerating tail of Hemidactylus flaviviridis. Acta Histochem., 122(1):151464, 2020.

Poetschke, J. \& Gauglitz, G. G. Current options for the treatment of pathological scarring. J. Dtsch. Dermatol. Ges., 14(5):467-77, 2016.

Rafii, S.; Butler, J. M. \& Ding, B. S. Angiocrine functions of organ-specific endothelial cells. Nature, 529(7586):316-25, 2016.

Seifert, A. W.; Kiama, S. G.; Seifert, M. G.; Goheen, J. R.; Palmer, T. M. \& Maden, M. Skin shedding and tissue regeneration in African spiny mice (Acomys). Nature, 489(7417):561-5, 2012.

Skalli, O.; Pelte, M. F.; Peclet, M. C.; Gabbiani, G.; Gugliotta, P.; Bussolati, G.; Ravazzola, M. \& Orci, L. Alpha-smooth muscle actin, a differentiation marker of smooth muscle cells, is present in microfilamentous bundles of pericytes. J. Histochem. Cytochem., 37(3):315-21, 1989

Smith, D. A.; Barker, I. K. \& Allen, O. B. The effect of ambient temperature and type of wound on healing of cutaneous wounds in the common garter snake (Thamnophis sirtalis). Can. J. Vet. Res., 52(1):120-8, 1988.

Stoica, A. E.; Grumezescu, A. M.; Hermenean, A. O.; Andronescu, E. \& Vasile, B. S. Scar-free healing: current concepts and future perspectives. Nanomaterials (Basel), 10(11):2179, 2020.

Wu, P.; Alibardi, L. \& Chuong, C. M. Regeneration of reptilian scales after wounding: neogenesis, regional difference, and molecular modules. Regeneration (Oxf.), 1(1):15-26, 2014.

Yang, C.; Zhang, H.; Kou, Z.; Zhang, Y.; Gao, Z. \& Liu, B. Histology and immunocytochemical localization of glial fibrillary acidic protein in the inner ear of Scincella tsinlingensis. Int. J. Morphol., 39(2):497$505,2021$.

Yu, L.; Yan, M.; Simkin, J.; Ketcham, P. D.; Leininger, E.; Han, M. \& Muneoka, K. Angiogenesis is inhibitory for mammalian digit regeneration. Regeneration (Oxf.), 1(3):33-46, 2014.

Corresponding author:

Chun Yang, Assoc. Prof.

Modern College of Arts and Sciences

Shanxi Normal University

Linfen

Shanxi Province

CHINA

E-mail: yangchun774@163.com

Received: 26-04-2021

Accepted: 29-05-2021 